\title{
ANALISA PERANCANGAN SISTEM INFORMASI PEMESANAN PADA WEDDING ORGANIZER BERBASIS WEB (STUDI KASUS: JFS WEDDING ORGANIZER CAKUNG)
}

\author{
Hanna Lusti ${ }^{1}$, Fajar Masya ${ }^{2}$ \\ 1,2 Universitas Mercu Buana \\ Jl. Raya Kranggan No.6 RT006 RW008 Jatiraden, Kec. Jatisampurna, Kota Bekasi, Jawa Barat 17433 \\ 141815210033@student.mercubuana.ac.id,. ${ }^{2}$ fajar.masya@mercubuana.ac.id
}

Abstrak- JFS Wedding Organizer berada di J1.Raya Bekasi KM.23 No.30, Cakung- Jakarta Timur. JFS Wedding Organizer merupakan suatu pelayanan jasa pernikahan yang ada di Jakarta Timur yang menyediakan beberapa jenis jasa pernikahan dan paket pernikahan yang pemesanannya masih secara manual. Kendala yang dihadapi oleh calon pengantin adalah Minimnya informasi yang dapat dijadikan acuan dalam pengambilan keputusan tentang Resepsi Pernikahan serta persiapan pernikahan yang disesuaikan dengan biaya (budget) calon pengantin. Oleh sebab itu penulis ingin membuat perancangan mengenai pemesanan dan informasi mengenai pernikahan. Website Wedding Planner Berbasis Web ini dapat memberikan kemudahan dalam pemesanan paket secara online, baik paket yang telah ditentukan maupun pilihan secara manual dan otomatis. Dengan adanya fitur-fitur serta konten yang membantu sharing informasi antara calon pengantin dengan pihak Wedding Or-ganizer.

Kata Kunci-Resepsi Pernikahan, Pemesanan, Wedding Planner, Web.

Abstract- JFS Wedding Organizer is located at J1.Raya Bekasi KM. 23 No.30, Cakung- East Jakarta. JFS Wedding Organizer is a wedding service in East Jakarta that provides several types of wedding services and wedding packages that are ordered manually. The obstacle faced by the bride and groom is the lack of information that can be used as a reference in making decisions about the Wedding Reception and wedding preparations that are tailored to the cost (budget) of the bride and groom. Therefore the author wants to make a design regarding reservations and information about marriage.

This Web-Based Wedding Planner Website can provide convenience in ordering packages online, both predetermined packages and choices manually and automatically. With the features and content that helps sharing information be-tween the bride and groom with the Wedding Organizer.

Keywords - Wedding Reception, Booking, Wedding Planner, Web

\section{PENDAHULUAN}

Wedding Organizer adalah suatu jasa yang memberikan pelayanan khusus secara pribadi yang bertujuan untuk membantu calon pengantin dan keluarga calon pengantin dari mulai perencanaan (planning) sampai tahap pelaksanaan. Wedding Organizer memberikan informasi mengenai berbagai macam hal yang berhubungan dengan acara pernikahan dan membantu merumuskan segala hal yang dibutuhkan pada saat pernikahan. Wedding Organizer memberikan solusi mulai dari tata rias, dekorasi, prewedding, gedung, catering dan segala sesuatu yang dibutuhkan pada saat acara pernikahan berlangsung. JFS Wedding Organizer merupakan suatu pelayanan jasa pernikahan yang ada di Jakarta Timur yang menyediakan beberapa jenis jasa pernikahan dan paket pernikahan yang pemesanannya masih secara manual. Hal ini menyebabkan sering di jumpai masalah calon pengantin tidak dapat menemui pemilik karena sedang tidak berada di tempat sehingga calon pengantin harus datang langsung ke JFS wedding Organizer untuk memesan atau sekedar mengetahui informasi layanan jasa yang disediakan pada wedding organizer tersebut, konfirmasi pembayarannya masih harus datang ke tempat wedding organizer atau melalui by phone. Oleh Karena itu JFS Wedding Organizer tentu harus lebih meningkatkan pelayanan yang dimiliki agar penggelolaan data menjadi baik dan rapi, sehingga dapat menghasilkan informasi yang lebih akurat dan dapat mengefektifkan waktu. Sistem Informasi merupakan salah satu cara untuk memudahkan layanan-layanan yang masih secara manual menjadi terkomputerisasi. Sistem informasi yang bersifat online memungkinkan dapat membantu memaksimalkan pelayanan yang ada pada wedding organizer. Dengan melihat beberapa kekurangan pada pelayanan sistem, Karena hal tersebut pada tugas akhir ini penulis memilih topik "Analisa Perancangan Sistem Informasi Pemesanan pada Wedding Organizer (Studi Kasus: JFS Wedding Organizer)" agar pengguna yang ingin mencari informasi serta 
pemesanan paket pernikahan bisa langsung melihat dan mencari di website ini.

\section{METODE PENELITIAN}

\section{A. Teknik Pengumpulan Data}

Teknik pengumpulan data yang dilakukan dalam

Page | 163 penelitian ini adalah :

1. Studi Pustaka

Mencari sumber buku, artikel, dan literatur internet yang berhubungan dengan topik penelitian .kemudian mempelajari dan memahami materi tersebut sebagai penunjang dalam penelitian.

2. Wawancara

Metode pengumpulan data dengan wawancara bertujuan untukmengumpulkan informasi dengan melakukan tanya jawab secara langsung dengan pihak JFS Wedding Organizer dan beberapa orang mengenai efektifitas web Wedding Planner ini.

\section{B. Diagram Alir Penelitian}

Diagram alir dibawah ini merupakan langkahlangkah untuk mendukung proses penelitian, beriktut tahapan penelitian:

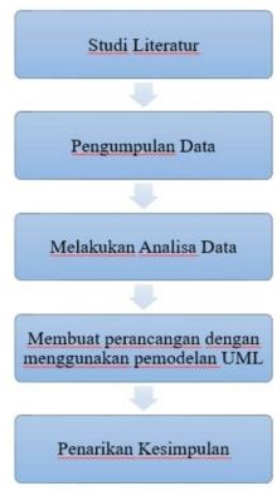

Gbr 1. Diagram Alir Penelitian

\section{Studi Literatur}

Studi literatur digunakan sebagai landasan teori dalam penyelesaian masalah secara ilmiah. Studi literatur dilakukan untuk menambah wawasan dan pengetahuan mengenai permasalahan yang akan dibahas dan menentukan metode yang cocok untuk memecahkan masalah yang sedang dihadapi perusahaan. Dalam tahap ini menggunakan berbagai jurnal dan sumber buku yang mendukung tentang penelitian ini, yang menjadi referensi dan acuan dalam penelitian.

2. Pengumpulan Data

Tahap selanjutnya adalah pengumpulan data yang nantinya digunakan untuk mendukung dan memecahkan permasalahan yang ada. Dalam pengumpulan data terlebih dahulu menetapkan sumber data, dalam penelitian ini menggunakan data primer sebagai pendukung sumber data yaitu melalui wawancara dengan staff atau karyawan JFS Wedding Organizer.

\section{Melakukan Analisa Data}

Melakukan analisa data bertujuan untuk menganalisa sistem dan membuat pemodelan data yang saat ini sedang berjalan di JFS Wedding Organizer dengan maksud untuk menemukan informasi yang bermanfaat untuk penelitian, kemudian membuat usulan rancangan sistem berdasarkan kebutuhan dan diberikan gambaran mengenai sistem yang sedang berjalan tersebut.

4. Membuat perancangan dengan menggunakan pemodelan UML

Setelah mendapatkan analisa kebutuhan pada JFS Wedding Organizer adalah menghasilkan rancangan yang memenuhi kebutuhan system informasi pemesanan paket pernikahan yang ditentukan selama tahap analisis dan database. Pada tahap penelitian ini rancangan menggunakan pemodelan UML (Unified Language Modelling). Pada pemodelan UML akan menghasilkan rancangan seperti Use case diagram yang menggambarkan hubungan antara actor dan system. Activity diagram menjelaskan alur aktifitas pada proses bisnis JFS Wedding Organizer.

5. Penarikan Kesimpulan

Pada tahapan ini kesimpulan merupakan hasil akhir yang diharapkan mampu menjawab tujuan penelitian yang berdasarkan dari hasil pengumpulan data dan analisa data. Selanjutnya memberikan saran kemungkinan penelitian lanjutan dari topic yang dibahas dalam penelitian.

\section{HASIL DAN PEMBAHASAN}

\section{A. Analisa Kebutuhan}

Tahap analisis sistem merupakan salah satu usaha mengidentifikasi kebutuhan dan spesifikasi sistem yang akan dicipatakan. Didalamnya akan dijabarkan apa saja entitas yang dilibatkan, proses yang dijalankan, serta output yang dihasilkan.

Berdasarkan analisis masalah yang dijabarkan diatas, maka sistem yang dibuat adalah sistem informasi pemesanan paket pernikahan dengan spesifikasi sistem sebagai berikut :

1. Sistem yang akan digunakan yaitu berbasis web.

2. Sistem menyediakan layanan untuk User atau calon pengantin yaitu melakukan untuk pendaftaran Customer, melihat Informasi paket, dan melakukan pemesanan.

3. Sistem menyediakan layanan untuk Owner atau staff JFS Wedding Organizer yaitu melakukan upload Informasi paket pernikahan, mengelola pemesanan dan membuat laporan pemesanan.

4. Sistem memberikan informasi seputar Informasi customer yang telah diinput oleh admin. Seperti melihat data pemesanan customer.

\section{B. Perancangan Sistem}

Perancangan sistem yang merupakan analisis kebutuhan fungsional ini akan mencakup Diagram UML: 
1. Use Case Diagram

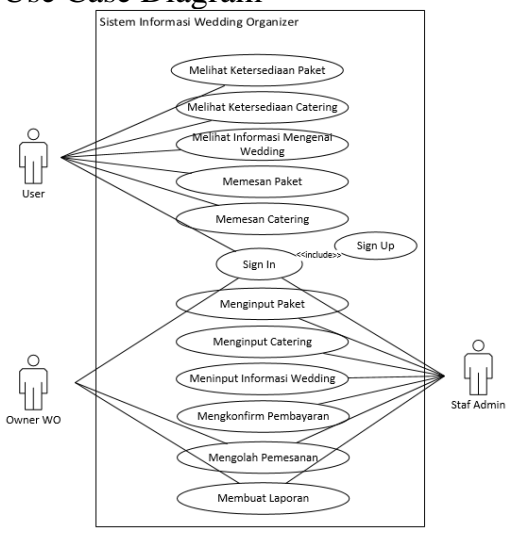

Gbr 2. Use Case Diagram

2. Activity Diagram

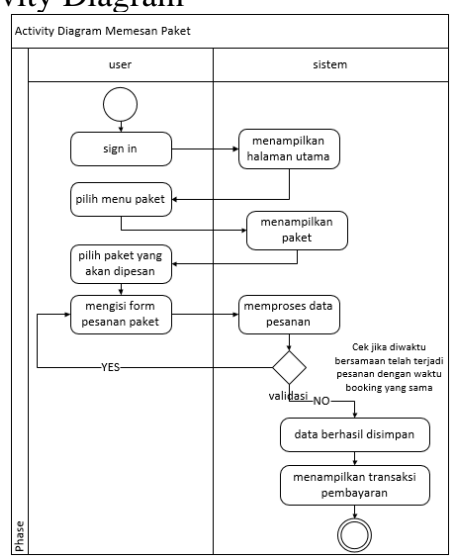

Gbr 3. Activity Diagram Memesan Paket

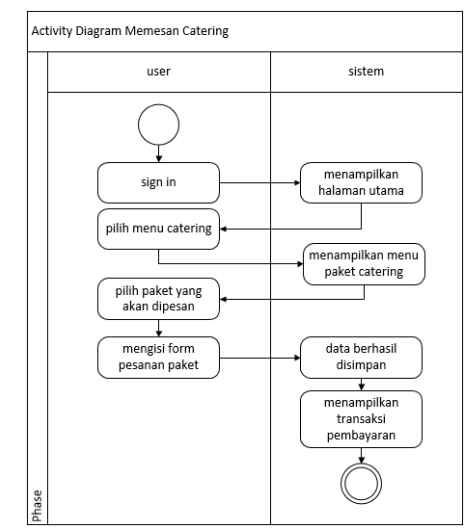

Gbr 4. Activity Diagram Memesan Catering

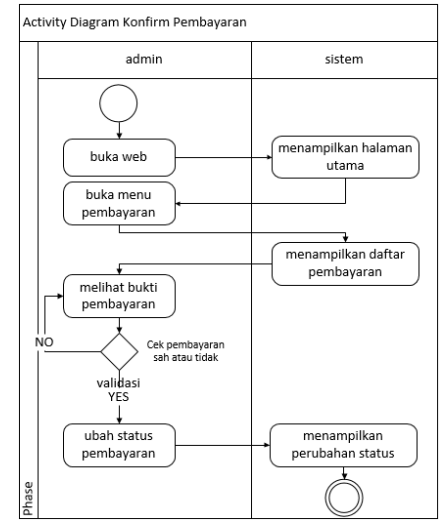

Gbr 5. Activity Diagram Konfirm Pembayaran

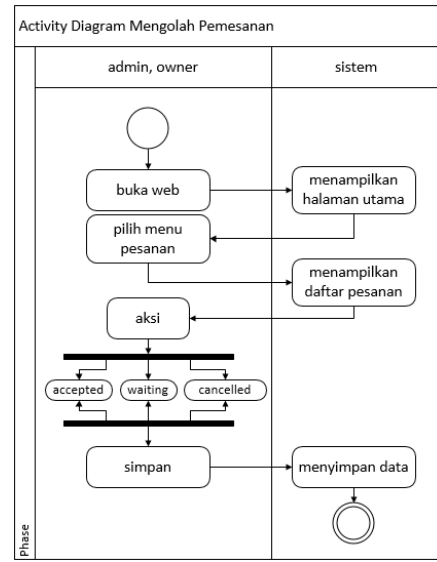

Gbr 6. Activity Diagram Mengolah Pemesanan

3. Class Diagram
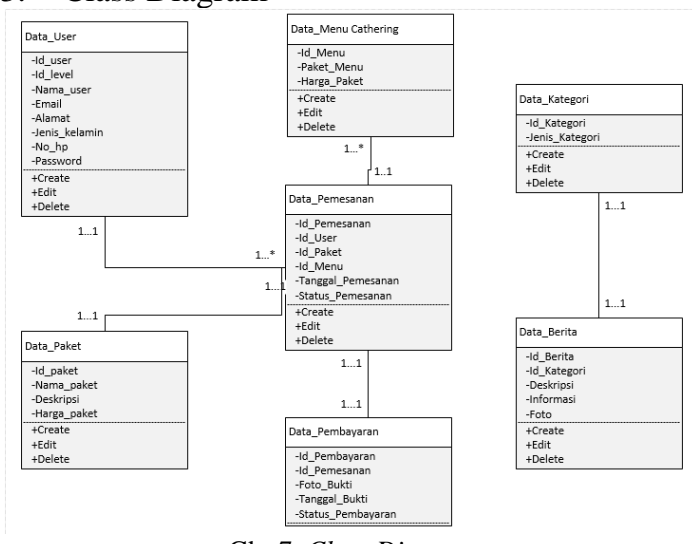

Gbr 7. Class Diagram

4. Perancangan Antar Muka

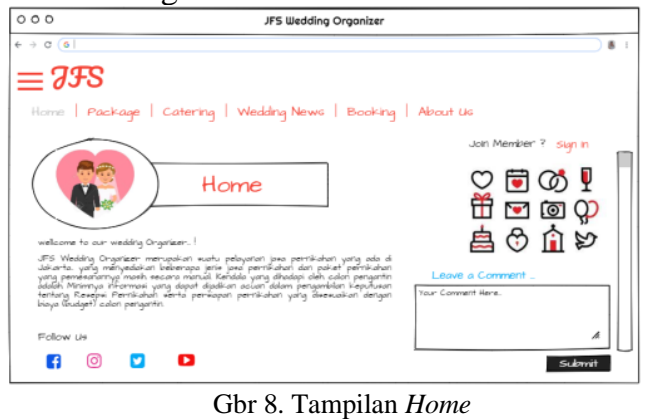




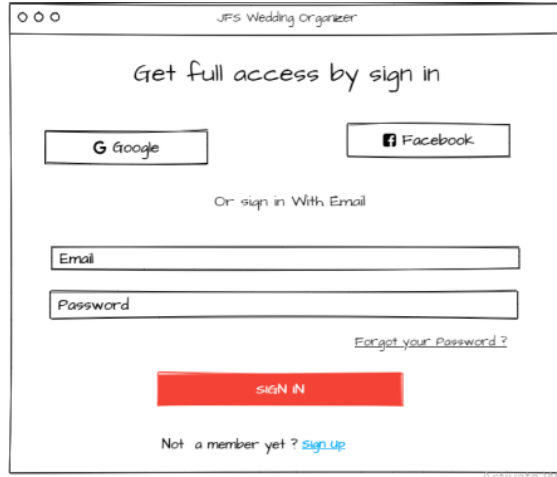

Gbr 9. Tampilan Sign In

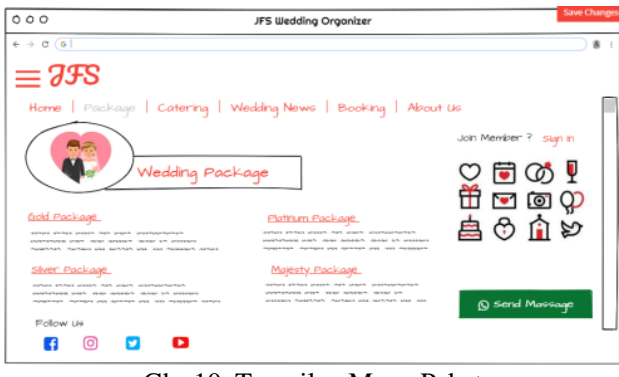

Gbr 10. Tampilan Menu Paket

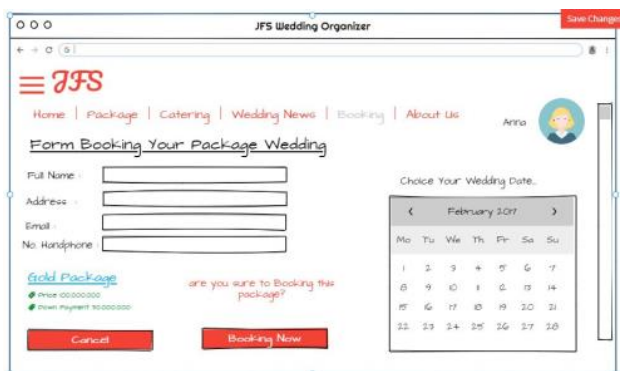

Gbr 11. Tampilan Halaman Pemesenan

5. Perancangan Keluaran

TABEL I

TABEL PERANCANGAN KELUAR

\begin{tabular}{|c|c|c|}
\hline No & Kasus & Tabel \\
\hline 1 & Daftar seluruh user & Data_user \\
\hline 2 & Daftar seluruh paket & Data_paket \\
\hline 3 & $\begin{array}{l}\text { Daftar seluruh } \\
\text { catering }\end{array}$ & Data_catering \\
\hline 4 & $\begin{array}{l}\text { Laporan Pemesanan } \\
\text { (Bulanan , Tahunan) }\end{array}$ & $\begin{array}{l}\text { Data_pembayar } \\
\text { an, } \\
\text { data_pemesanan }\end{array}$ \\
\hline 5 & $\begin{array}{l}\text { Laporan Bukti } \\
\text { Pembayaran }\end{array}$ & $\begin{array}{l}\text { Data_pembayar } \\
\text { an }\end{array}$ \\
\hline 6 & $\begin{array}{l}\text { Daftar pemesanan } \\
\text { (diterima, ditolak, } \\
\text { dan selesai) }\end{array}$ & $\begin{array}{l}\text { Data_pemesana } \\
\mathrm{n}\end{array}$ \\
\hline
\end{tabular}

\section{IV.PENUTUP}

Dengan adanya perancangan sistem informasi pemesanan wedding organizer berbasis web ini, maka proses kegiatan pemesanan paket pernikahan menjadi lebih hemat waktu dan tenaga. Sistem informasi ini juga dapat membantu owner JFS wedding organizer untuk mendapatkan custumer baru dan lebih mudah dalam berkomunikasi mengenai paket pernikahan. Aplikasi system informasi pemesanan wedding organizer ini dapat dikembangkan tidak hanya untuk memesan mengenai paket pernikahan pada wedding organizer saja, tetapi bisa diperluas pada acara-acara besar lainnya, seperti event organizer.

\section{UCAPAN TERIMA KASIH}

Ucapan terima kasih ditujukan kepada seluruh pihak terkait yang turut membantu dengan dukungan baik itu moril maupun materil.

\section{REFERENSI}

[1] Kusrini. 2006. Strategi Perancangan Dan Pengelolaan Basis Data. Yogyakarta: Andi Publisher. Hal 2.

[2] Prasetyo,Eko. 2008. Pemrograman Web PHP \& MySQL. Yogyakarta: Graha Ilmu. Hal 19.

[3] Yeni Kustiyahningsih dan Devie Rosa Anamisa. 2011. Pemograman Basis Data Berbasis Web Menggunakan PHP dan MySQL. Yogyakarta: Graha Ilmu. Hal 146.M. Wegmuller, J. P. von der Weid, P. Oberson, and N. Gisin, "High resolution fiber distributed measurements with coherent OFDR," in Proc. ECOC'00, 2000, paper 11.3.4, p. 109 .

[4] Ina Najiyah, Surhayanto. 2017. Sistem Informasi Wedding Planner Berbasis Web.

[5] (2017) The IEEE website [Online] Available: http://www.eopapua.com/detailpost-18-apa-itu-weddingorganizer

[6] Ade wiwid, Sri Harjunawati. 2017. Perancangan Sistem Informasi Transaksi Penyewaan Wedding Organizer pada CV.Denis Citra Mandiri Bekasi.

[7] Pressman R. S., 2012, Rekayasa Perangkat Lunak (Edisi 7 Buku 1), Andi, Yogyakarta. Hal 46. 